\title{
Vivendo em rede: a prática da linguagem nas redes sociais
}

\author{
Adriana Emerim Borges* \\ Ana Carolina Lersch Eidam**
}

\begin{abstract}
Resumo: O presente trabalho pretende relatar a experiência desenvolvida em uma turma de terceiro ano do Ensino Médio, que envolveu a disciplina de Língua Portuguesa e o Laboratório de Informática da escola. A sequência didática contou com recursos variados: da exibição do filme que foi o ponto inicial da proposta à criação de um grupo de discussão, passando por atividades de leitura e de escrita, exercícios de argumentação oral e escrita, até a simulação de um tribunal de júri.
\end{abstract}

Palavras-chave: Internet; rede; ensino; língua; escrita.

Abstract: this paper intends to report a teaching experience developed in a High School class, which involved Portuguese classes and the school computer lab. The instructional sequence had various tasks, including a film session, the starting to this teaching project, which included, moreover, the creation of a discussion group, reading and writing activities, even playing a grand jury.

Keywords: Internet; net; teaching; language; writing

Professora de Língua Portuguesa. Mestre em Letras (PUCRS) e Doutoranda em Letras (PUCRS). E-mail: adrianaemerim@gmail.com

** Graduanda em Comunicação Social - Habilitação em Jornalismo pela PUCRS. E-mail: analersch@gmail.com 


\section{Introdução}

A sala de aula vem se tornando, cada vez mais, um espaço interativo, que comporta imensas possibilidades. A facilidade de acesso à Internet, sua variedade de suportes e a perda crescente de controle do que está sendo acessado configuram um desafio dentro do espaço escolar. A utilização de forma positiva deste universo de caminhos tende a apresentar-se como trabalhosa e, por vezes, impossível. Negar, no entanto, que novas ferramentas existem e podem apresentar bons resultados se utilizadas adequadamente, significa perder oportunidades de trocas e de aprendizado mútuo. A permanência na zona de conforto, tanto do educador como do aluno, pode ser um desperdício de recursos que estão à disposição e merecem ser discutidos.

Foi a partir desta perspectiva, de trazer para a sala de aula novas plataformas de aprendizagem, que se buscou a discussão sobre as redes sociais, seus limites e suas possibilidades, aliada ao estudo das possibilidades de estudo das linguagens próprias do ambiente virtual. Para tanto, o Laboratório de Informática da Escola Luterana de Ensino Médio Martinho Lutero - Cachoeirinha/RS, em conjunto com a disciplina de Língua Portuguesa, abriu um espaço de estudo e reflexão sobre o tema. $\mathrm{O}$ relato aqui apresentado diz respeito a este trabalho, que foi desenvolvido com alunos de uma turma de terceiro ano de Ensino Médio da Escola.

As etapas desenvolvidas foram: uma sessão de cinema com o filme "A Rede Social" de David Fincher, com alunos de $7^{\text {a }}$ série ao Ensino Médio, propostas de leitura e escrita que proporcionassem a estruturação de uma visão crítica e analítica sobre o tema da utilização das redes e a simulação de um tribunal de júri, composto por defesa e acusação, em torno das questões anteriormente debatidas. Esse trabalho culminou em um grupo de discussão na internet que expunha as opiniões dos alunos sobre o tema, oportunidade na qual educadores e estudantes puderam realizar trocas e defender suas opiniões. 


\section{O Processo}

Em Sem medo do Internetês, Tadeu Rossato Bisognin escreve:

É inegável a relação entre língua, linguagem e sociedade. Saussure $(2004$, p. 14) a isso já se referiu quando afirmou que "a linguagem é um fato social". Acrescentou ainda que "os costumes duma nação têm repercussão na língua e, por outro lado, é em grande parte a língua que constitui a Nação" (SAUSSURE, 2004, p. 29). As línguas refletem sociedades e suas épocas, sendo o léxico a parte que mais nitidamente acompanha as alterações sociais. Uma sociedade com novas descobertas necessita nomeá las, cria novos vocábulos ou amplia a significação dos já existentes. O vocabulário e também a sua forma de expressão indicam a evolução e o estado de desenvolvimento científico, tecnológico e cultural de uma sociedade. É possível afirmar que, sob alguns aspectos, o século XX foi pródigo em transformações, culminando com o surgimento do computador e da comunicação em rede. Nesse ambiente cultural marcado pelo advento da Internet, destacamos o componente lexical em situação de escrita. A Internet é um novo ambiente de enunciação cultural, com múltiplas linguagens, possibilidade de interações, velocidade acelerada de informação e estrutura multimidiática. Ela suscita e expressa um ambiente de comunicação diferenciado. Isso pode ser percebido até nas formas de escrever utilizadas pelos internautas, principalmente pelos jovens, na comunicação eletrônica: interferem sobre a escrita culta padrão para interagir. Escrever teclando no computador, especialmente on line, é certamente algo que induziu a inovações, principalmente pela velocidade que se precisa dar àquilo que se transmite por escrito. Como é possível notar, a Internet revolucionou o mundo das comunicações em muito pouco tempo como nenhuma outra invenção antes fez. Nenhuma tecnologia ou instrumento anteriormente empregado conseguiu uma tão grande sinergia $(2009$, p. 13).

Desconsiderar, portanto, a enorme influência das tecnologias sociais, quaisquer que sejam, no ensino da Língua Portuguesa, torna-se tarefa impossível para a professora ou o professor. Ao considerarmos o uso da Internet e de suas amplas possibilidades no ensino da língua, passamos a contar com um recurso didático extremamente rico, que, aliado aos demais suportes textuais, como jornais impressos, revistas e livros, podem efetivamente trazer a "língua viva", em toda a sua riqueza e dinamismo para o ambiente escolar. 
É a partir dessa perspectiva que as aulas de Língua Portuguesa no Ensino Médio são planejadas e desenvolvidas. Para tanto, faz-se necessário o apoio de setores escolares como biblioteca, setor de recursos audiovisuais e laboratório de informática.

A experiência que relatamos a seguir teve sua gênese em uma iniciativa do LABIN - Laboratório de Informática da Escola Luterana de Ensino Médio Martinho Lutero, em Cachoeirinha - RS, cujo objetivo era abordar a discussão acerca das redes sociais, amplamente divulgada em todas as formas de mídia nos últimos tempos e que interessa sobremaneira a todos os sujeitos em qualquer espaço educativo. Vista a presença massiva nesses locais através de diversos suportes - a exemplo da utilização de celulares, Ipads, Iphones, netbooks e notebooks nas salas de aula de todos os níveis de ensino. A proposta teve início com uma sessão do filme $A$ rede social, a qual foi assistida pelos alunos de $7^{\mathrm{a}}$ série do Ensino Fundamental ao $3^{\mathrm{o}}$ ano do Ensino Médio. As Figuras 1 e 2 referem-se à fotos da seção de cinema realizada com os alunos na Escola.

Figura 1:

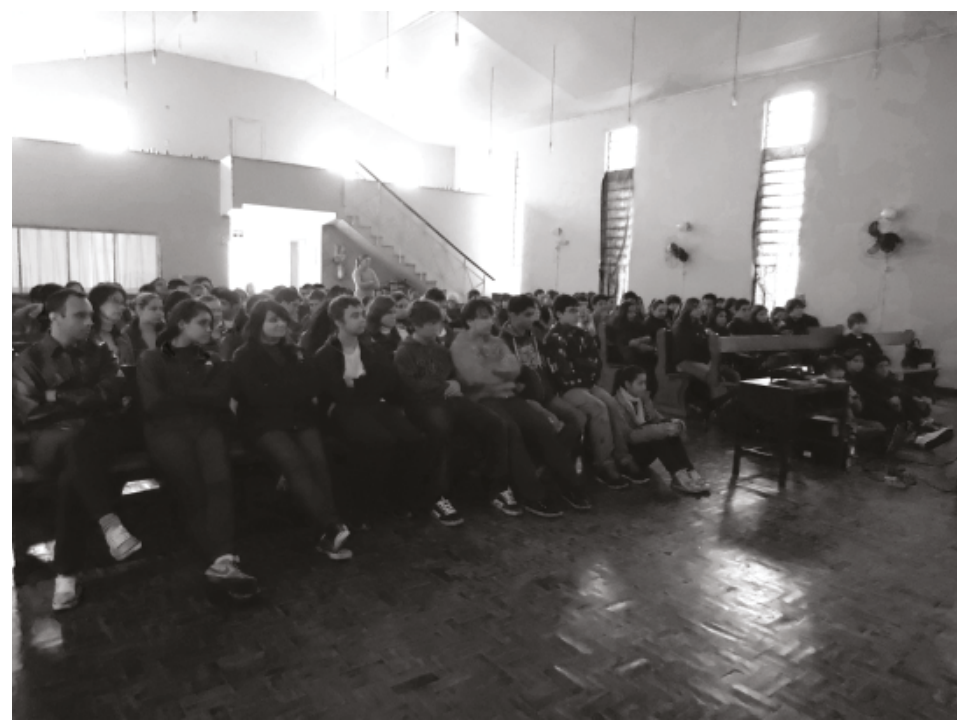


Figura 2:

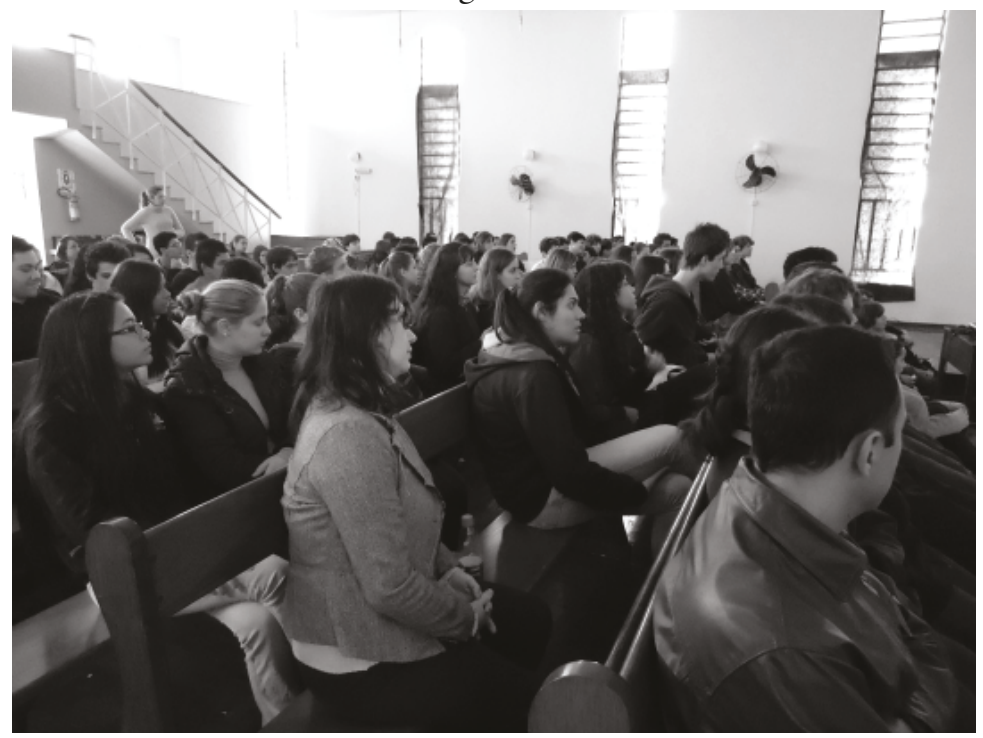

A disciplina de Língua Portuguesa, a partir de então, inserese no projeto, propondo-se a dar continuidade à ideia inicial de provocar o debate acerca das redes sociais e de seu uso pelos jovens, em especial os jovens dessa comunidade escolar. Elaborada a sequência didática, e selecionado o grupo-alvo da proposta $\left(3^{\circ}\right.$ ano do Ensino Médio), cuja escolha baseou-se no fato de ter o texto dissertativo-argumentativo como gênero textual proposto para as atividades de leitura e escrita no semestre em questão, iniciaram-se alguns trabalhos, os quais passamos a descrever.

O grupo passou a ter contato, em sala de aula, com textos dos mais diversos gêneros, que tinham como tema comum as redes sociais, a relação dos usuários com redes como Orkut, Facebook, MSN, Formspring e Tivitter, além de questões como privacidade, exposição de dados pessoais e de imagens e o tempo dedicado ao que os alunos passaram a denominar "vida virtual", noção construída em oposição ao conceito que tinham de "vida real". A expressão "vida real", segundo o grupo, era o tempo 
dedicado a atividades como os estudos, o trabalho, o lazer e à convivência com familiares, colegas e amigos. Também textos que tematizavam os novos suportes foram lidos e trabalhados dentro das aulas, nas quais o estudo do tema foi utilizado como base para questões de compreensão e de interpretação. Após as leituras e as discussóes das questôes propostas, os textos eram expostos em um mural temático e, a seguir, passava-se à produção de textos escritos, observando-se sempre a estrutura do gênero dissertativo-argumentativo. A Figura 3 apresenta uma parte do mural criado através de um grupo de discussões na Internet, em que alunos e professores puderam interagir.

Figura 3: Mural do grupo de discussão na Internet

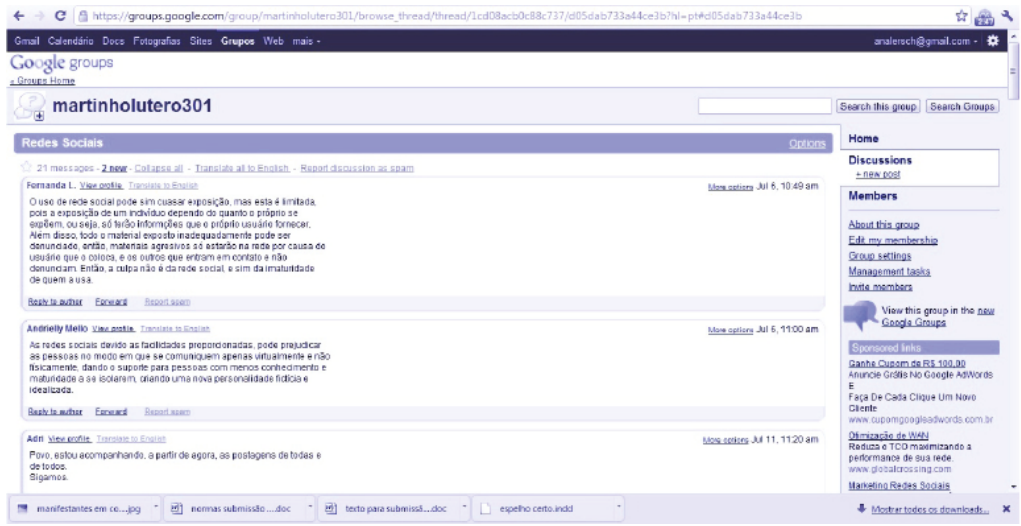

A primeira produção escrita foi revisada e devolvida, e, então, os textos reescritos foram postados em um grupo de discussão criado especialmente para esse trabalho e administrado pelo LABIN, que acabou, posteriormente, por tornar-se um instrumento de comunicação para a disciplina. As figuras 4 e 5 referem-se ao espaço para postagem e discussão oferecido aos alunos. 
Figura 4: Alunos no LABIN

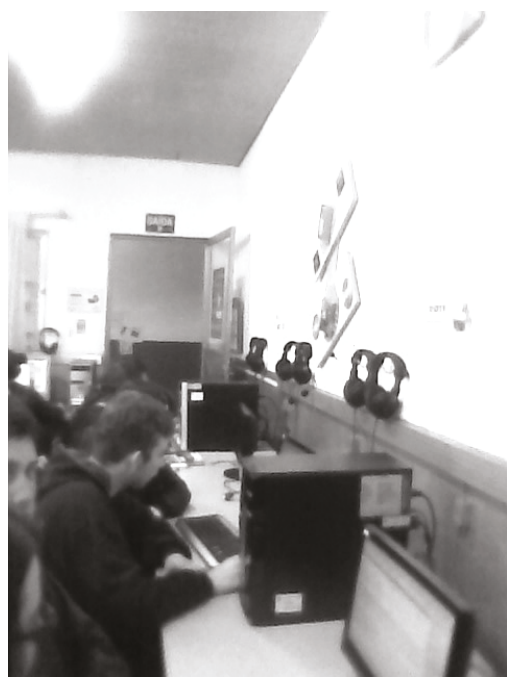

Figura 5: Alunos postando os textos

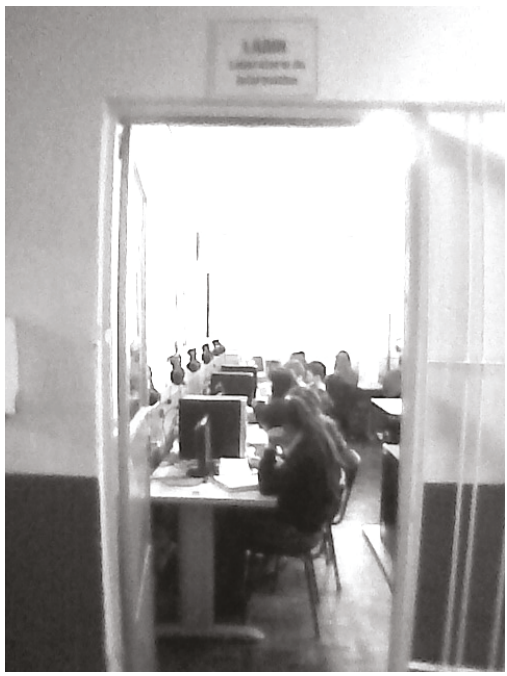

Alguns textos argumentativos produzidos e postados pelos alunos estão abaixo reproduzidos:

"É um mundo onde tudo se move depressa e muda o tempo todo, onde as relações são rapidamente descartadas pelo clique do mouse, onde se pode deletar o perfil que você não gosta e trocá-lo por uma identidade mais aceitável em um piscar dos olhos."

Aluno: Vinícius Cassol - Turma 301 
"O conceito original das redes sociais, em minha opinião, é facilitar a comunicação entre as pessoas, proporcionandonos a chance de reencontrar antigos amigos, assim como falar com pessoas distantes geograficamente. Além disso, é possível compartilhar pensamentos, ideias, etc. No entanto uma característica que é natural do ser humano, a curiosidade, acaba desvirtuando a essência desses sites. $\mathrm{O}$ objetivo passa a ser o conhecimento da vida alheia e julgá-la, sem levar em consideração que o conteúdo exposto, muitas vezes, é superficial.” Aluna: Renata Engel - Turma 301

"O papel dos pais é fundamental e estes devem tentar saber e acompanhar o que os filhos menores fazem na Internet. Por exemplo, se você tem filhos ou filhas menores, deve procurar pelos perfis dos seus filhos nas redes sociais e verificar que tipo de informações e fotos tornaram públicas. Tente perceber também com que tipo de pessoas eles falam nas salas de chat e no MSN e previna-os para os riscos a que estão sujeitos. Mantenha-se atento, a prevenção é o melhor remédio.” Aluno: Douglas Roth - Turma 301

A atividade planejada para o encerramento das discussões em torno das redes sociais envolveu a simulação de um tribunal de júri, para o qual a turma foi dividida em dois grupos, que deveriam apontar aspectos positivos e negativos nas atitudes dos usuários de redes como as já citadas. Um dos grupos encaminhou-se para a biblioteca, enquanto o outro permaneceu em sala de aula, com o objetivo de prepararem as estratégias argumentativas que seriam utilizadas no debate. Os dois grupos receberam, previamente, orientações sobre seleção e previsão de argumentos e contra-argumentos, que foram utilizadas, diga-se, de forma a superar expectativas, na medida em que, ao iniciar-se a dinâmica, desempenharam com toda a propriedade as funções de 
"acusação" e de "defesa", selecionaram argumentos pertinentes e fizeram uso de recursos próprios do registro oral, sem, contudo, desconsiderar a norma culta, sabedores que eram de que esse era um dos critérios propostos para a atividade.

\section{Conclusão}

Retomamos, nestas últimas palavras, as premissas que se fizeram presentes na proposta de trabalho relatada neste texto e que sintetizam parte de nossa concepção de ensino de língua materna:

[...] o domínio da língua tem estreita relação com a possibilidade de plena participação social, já que é por meio da língua que o homem se comunica, tem acesso à informação, mostra e defende seus pontos de vista, partilha ou constrói visões de mundo, isto é, produz conhecimento (BISOGNIN, 2009, p.169).

Ao fim das atividades desenvolvidas a partir da proposta iniciada no LABIN e levada à disciplina de Língua Portuguesa, mais uma vez confirmamos a importância de realizar-se um trabalho que insira a leitura e a escrita em seu lugar de fato: o lugar da língua viva e dinâmica, "em constante evolução e inserida nas práticas sociais” (BISOGNIN, 2009, p. 169), e que se contraponha a meras estratégias de "preenchimento de linhas em branco", prática comum na maioria dos textos escolares.

\section{Referências}

BISOGNIN, Tadeu Rossato. Sem medo do Internetês. Porto Alegre: AGE, 2009.

A REDE SOCIAL. David Fincher (dir.). EUA, Columbia Pictures/ Relativity Media / Michael De Luca Productions/ Scott Rudin Productions/ Trigger Street Productions, 2010, colorido, 117min. Título original: The Social Network. 